\title{
CYTOPROTECTION AND HEALING: TWO UNEQUAL BRETHREN
}

\author{
F. HALTER ${ }^{1 *}$, B. PESKAR ${ }^{2}$ K.D. RAINSFORD ${ }^{3}$ AND A. SCHMASSMANN ${ }^{1}$ \\ ${ }^{1}$ Department of Medicine, Gastrointestinal Unit, University of Bern, Inselspital, 3010 \\ Bern, Switzerland; '2Department of Experimental Clinical Medicine, Ruhr University, \\ Germany; ${ }^{3}$ Division of Biomedical Sciences, Sheffield Hallam University, UK \\ *Correspondence
}

\section{ABSTRACT}

Halter F, Peskar B, Rainsford KD, Schmassmann A. Cytoprotectoin and healing: two unequal brethren. Inflammopharmacology. 1997;5:407-414.

\begin{abstract}
The promotion of the concept of cytoprotection has fostered hopes that the use of co-prescribed mucosal protective agents would revolutionize the prevention of NSAID-induced ulcers and supply the basis for novel ulcer therapy. Prostaglandins do not, however, accelerate ulcer healing when applied at doses that exert an unequivocal cytoprotective activity. Attempts have therefore been made in recent years to create new less-toxic NSAIDs, such as combined lipoxygenase/cyclo-oxygenase inhibitors, NSAIDs coupled to an NO donor and so-called COX-2 inhibitors. All these preparations do in fact exert a diminished gastrointestinal toxicity. There is however increasing evidence accumulating from studies performed in and outside our laboratories that in chronic ulcer models their increased gastrointestinal tolerance is not necessarily reflected by non-interference with ulcer healing. It is thus mandatory to distinguish between cytoprotective and healing properties of drugs interfering with the cyclo-oxygenase pathway.
\end{abstract}

Keywords: cytoprotection, NSAIDs, ulcer

Chronic infection with Helicobacter pylori and non-steroidal anti-inflammatory drugs (NSAIDs) represent the two most important pathogenic factors in peptic ulcer disease [1-3]. Since eradication of $H$. pylori can cure peptic ulcer disease in the majority of $H$. pylori-associated peptic ulcers, increasingly more attention is given to prevention and therapy of NSAID-induced ulcers. This is of particular importance since NSAIDs are highly liable to produce severe ulcer complications such as massive gastrointestinal haemorrhage or perforation from complicated peptic ulcers $[4,5]$. It is now increasingly recognized that the occurrence of such complications is not restricted to the stomach and duodenum but can also result from ulcers localized in the small and large bowel [6]. Chronic administration of NSAIDs produces gastroduodenal mucosal erosions in $35-60 \%$ of patients, ulcerations in $10-25 \%$, and severe gastrointestinal haemorrhage or perforation in $<1 \%[2,4,5]$. In experimental and clinical conditions, indomethacin delays gastric ulcer healing [7,8]. Among the mechanisms proposed for delayed healing are: (a) inhibition of synthesis of prostaglandins that are important for gastroduodenal mucosal defence [9-11], (b) inhibition of epithelial cell proliferation in the ulcer margin that is critical for re-epithelialization of the ulcer crater $[7,12,13]$, (c) inhibition of angiogenesis that is essential for nutrient supply in the ulcer bed [12] and, (d) inhibition of proliferation and function of myofibroblasts involved in remodelling and contraction of the granulation tissue in the ulcer bed $[12,14]$. 
NSAIDs inhibit prostaglandin synthesis by the gastric mucosa and thromboxane production by platelets so impairing platelet aggregation. Within $90 \mathrm{~min}$ of acute aspirin ingestion in humans, extensive intramucosal petechial haemorrhage becomes visible and this is, in part, related to promotion of bleeding from the antiplatelet actions of aspirin. With longer term ingestion, the number of erosions may diminish, possibly by a process of adaptation [15]. However, erosions, petechiae and superficial ulcers are quite common in patients on long-term maintenance treatment with NSAIDs. Moreover, it is not established why a small proportion of patients develop chronic ulcers yet others exhibit little or no mucosal damage.

The promotion of the concept of cytoprotection by the late André Robert [9] had fostered hopes that the use of co-prescribed mucosal protective agents would revolutionized the prevention of NSAID induced ulcers and supply the basis for novel ulcer therapy. The hopes were, however, only partially fulfilled. Thus, endoscopic studies have shown that the prostaglandin analogue misoprostol reduces the incidence of gastric and duodenal ulcers and the admission rate to hospital with ulcer complications [11]. Prostaglandins did not, however, revolutionize peptic ulcer therapy; they only exert modest ulcer healing at high acid-inhibitory doses [16]. Moreover, gastric biopsy lesions do not heal faster when diclofenac is combined with misoprostol treatment [17]. Profound acid suppression by high-dose proton pump inhibitors (PPIs) is, however, highly effective in the treatment of NSAID-induced gastroduodenal ulcerations both in man and experimental models $[7,12,18,19]$. The advantage of the PPIs against prostanoids in ulcer prevention therapy is better tolerance, whereas their limitation is based on the higher costs and possible undesirable side-effect of long-term anacidity (e.g. promotion of bacterial overgrowth with its theoretical carcinogenic potential).

\section{NOVEL NSAIDs AND THEIR TOXICITY IN ACUTE MODELS}

Numerous strategies have been used in recent years to develop new anti-inflammatory and analgesic drugs that spare the gastrointestinal tract.

Several groups are attempting to develop NSAIDs that predominantly inhibit effects on lipoxygenase or other particularly non-ulcerogenic pathways of lipid metabolism and/or which have antioxidant activity. Tebufelone, one of these compounds, displaying both lipoxygenase and cyclo-oxgenase activity, has been shown to be gastroprotective in various models of NSAID-induced injury [20,21].

Another strategy for developing gastrointestinal-sparing NSAIDs is the coupling of a nitric oxide-releasing moiety to a standard NSAID [22-29]. The rationale behind this strategy is that the nitric oxide (NO) released from these derivatives will exert beneficial effects on the mucosa by maintaining gastrointestinal blood flow and inhibiting adherence and activation of white blood cells with the gastrointestinal mucosa [22,23]. These promises are clearly fulfilled with regard to better acute tolerance and the results of one study suggest that experimental ulcer healing is not compromised by this treatment modality [23]. 
The most recent strategy is based on the recognition that cyclo-oxygenase (COX), the rate-limiting enzyme of prostaglandin (PG) synthesis exists in two forms, a constitutive COX-1 and an inducible COX-2, whereby the latter is activated in inflammatory exudates in rheumatic disease. By contrast PGs produced in normal gastric tissue are derived from COX-1 [30]. COX-2 inhibitors should thus theoretically be free of gastrointestinal toxicity. The specific COX-2 inhibitor, L-745,337, has indeed been shown to produce minimal toxicity in acute gastric models, including in studies from our own laboratories [31-33].

Hopes have been nourished for all the three groups of the above discussed novel NSAIDs, that these compounds will not compromise ulcer healing and possibly even accelerate ulcer healing.

\section{STUDIES ON HEALING OF CHRONIC EXPERIMENTAL ULCERS}

We have performed a detailed analysis aimed at investigating how each of the three above-mentioned NSAIDs would interfere with the complex healing kinetics of gastric ulcers. The studies were performed in a cryo-ulcer model in the rat which allows a very precise analysis of healing through repeat endoscopy with exact measurements of the residual ulcer size [12]. In summary female Wistar rats with an initial body weight of 200-220 $\mathrm{g}$ were used. To permit regular endoscopic control of the healing process, a fistula cannula of the type generally used for gastric secretion studies (inner diameter 8 $\mathrm{mm}$ ) was implanted in the forestomach under ether anaesthesia, three weeks prior to the onset of the study. After a 3-week recovery period, laparotomy was again performed in order to induce an experimental ulcer with a cryoprobe (outer diameter $6.5 \mathrm{~mm}$ ), which was placed on the gastric mucosa on the posterior wall of the central part of the corpus (duration $45 \mathrm{~s}$ ) to generate standardized ulcers. The size of the ulcer was measured every 2-3 days using a video-endoscopic system. An arthroscope with a $30^{\circ}$ oblique-viewing optical system (Stortz, Tuttlingen, FRG) was used in conjunction with an Olympus videocamera. For the examination, the rats were immobilized in Bollmann cages. Endoscopy required neither anaesthesia nor prior fasting. The stomach was irrigated via the fistula cannula to remove food particles. To record the size of the ulcer, a piece of calibrated paper (diameter $4 \mathrm{~mm}$ ) was introduced via the fistula cannula and positioned next to the ulcer with the tip of the endoscope In two series of experiments, healing of cryo-ulcers was sequentially studied over a 15-day treatment period. The objectives of the first study were to analyse the effects of tebufelone and nitrofenac on ulcer healing in the above described rat ulcer model. The doses of tebufelone were either 1 or $10 \mathrm{mg} / \mathrm{kg}$ ig twice daily, and that for nitrofenac $3.75 \mathrm{mg} / \mathrm{kg}$. ig twice daily. The comparators were placebo, omeprazole $40 \mu \mathrm{mol} / \mathrm{kg} \mathrm{sc}$, once daily, indomethacin $0.5 \mathrm{mg} / \mathrm{kg} \mathrm{sc}$, twice daily, diclofenac $2.5 \mathrm{mg} / \mathrm{kg}$ ig, twice daily, indomethacin $0.5 \mathrm{mg} / \mathrm{kg}$ sc twice daily + omeprazole $40 \mu \mathrm{mol} / \mathrm{kg}$ sc once daily. Rats were randomly treated with the above-mentioned medications for 15 days. 
$\mathbf{A}$

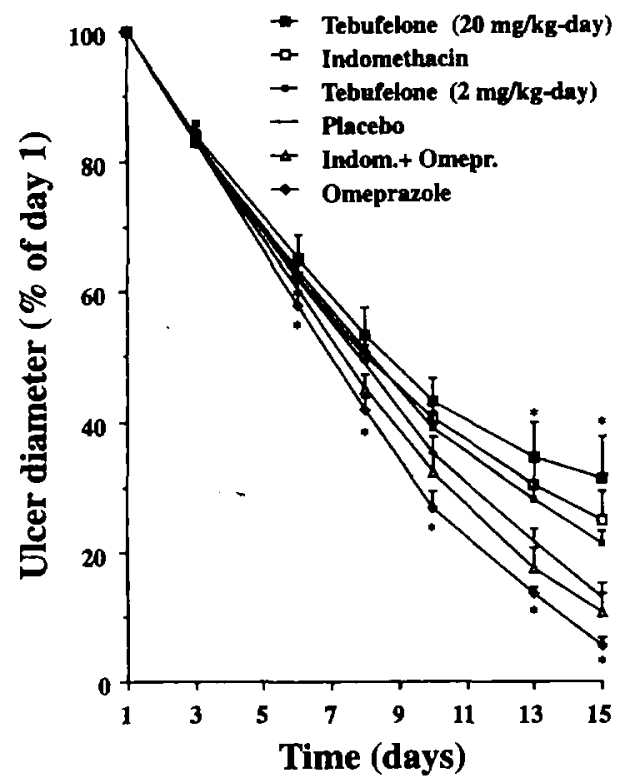

B

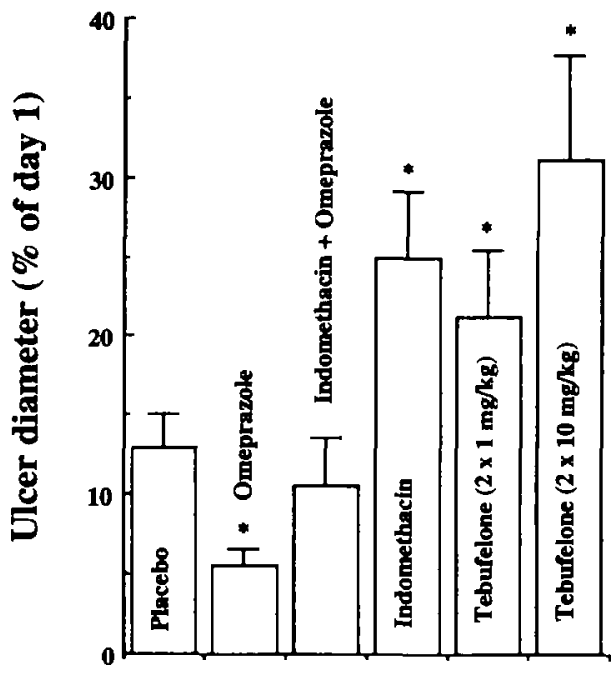

Figure 1. Ulcer healing curve assessed by video endoscopy. (A) The data indicate mean percentage residual ulcer size \pm SEM over the observation time points. (B) Residual ulcer size on day 15 as a percentage of the initial ulcer size on day $1 . p<0.05$ vs. placebo (ANOVA)

The objective of the second study was to examine the effects on ulcer healing of the COX-2 inhibitor, L-745,337. The doses used were $0.5 \mathrm{mg} / \mathrm{kg}, 2 \mathrm{mg} / \mathrm{kg}$ and $5 \mathrm{mg} / \mathrm{kg}$, twice daily ig for 15 days. The same control treatments were applied as in the tebufelone/nitrofenac study.

As shown in Figures 1 and 2, all the three novel NSAIDs similarly delayed healing of the cryo-ulcers by a pattern of interference with the healing kinetics similar to that of indomethacin or diclofenac. By contrast, healing was accelerated during omeprazole monotherapy. The healing delay induced by the NSAIDs became substantial only in the second treatment week, while omeprazole accelerated healing predominantly in the first week. Concomitant treatment with omeprazole reversed the healing kinetics under NSAID treatment to the placebo values, thus still partly interfering with the speedpromoting effect which omeprazole exerts on healing.

In the second study, the dose-response relationship for the inhibition of gastric ulcer healing rates from days 8-15 was compared between indomethacin, diclofenac and L$745,337(n=26)$ The ID 50 values were $0.4 \mathrm{mg} / \mathrm{kg}, 0.8 \mathrm{mg} / \mathrm{kg}$, and $1.7 \mathrm{mg} / \mathrm{kg}$ respectively (Figure 3). 
$\mathbf{A}$

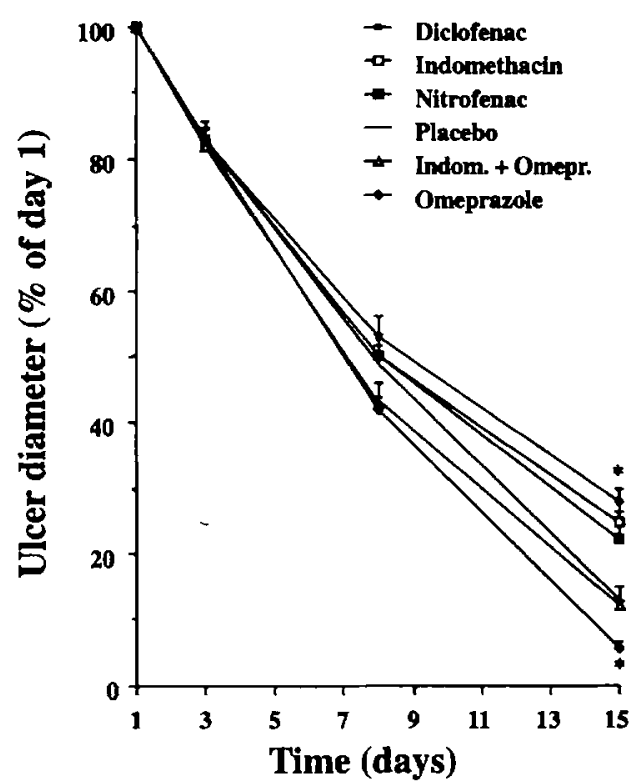

B

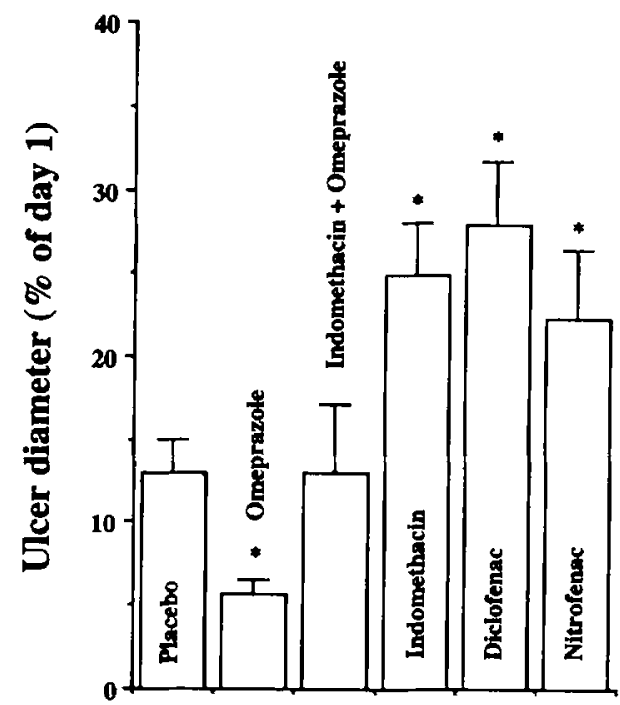

Figure 2. Ulcer healing curve assessed by video endoscopy: (A) The data indicate mean percentage residual ulcer size \pm SEM over the observation time points. (B) Residual ulcer size on day 15 as a percentage of the initial ulcer size on day $1 . p<0.05$ vs. placebo (ANOVA)

\section{PATHOPHYSIOLOGICAL BACKGROUND FOR INTERFERENCE OF NOVEL NSAIDS WITH ULCER HEALING}

In search of reasons for the interferenceon healing of the COX-2 inhibitor, L-745,337, microvessel density was quantified in the granulation tissue below the ulcer crater and compared with the known suppressive effects of conventional NSAIDs, such as indomethacin and diclofenac, on angiogenesis [12]. For all three compounds, a dosedependent inhibition of angiogenesis was verified. The $\mathrm{ID}_{50}$ values were $0.5 \mathrm{mg} / \mathrm{kg}$ for indomethacin, $1.0 \mathrm{mg} / \mathrm{kg}$ for diclofenac and $2.1 \mathrm{mg} / \mathrm{kg}$ for $\mathrm{L}-745,337$. COX-2 immunoreactivity was not detected in glandular cells but in endothelial cells and many macrophages and fibroblasts in the submucosa and the granulation tissue involved in the healing process during days $3-15$.

The result of our studies can be regarded as a further confirmation that increased tolerance of the gastric mucosa for those novel NSAIDs that are better tolerated by the intact gastric mucosa does not guarantee non-interference with ulcer healing. During ulcer healing angiogenesis is a rate-limiting factor and the observation made in our study that L-745,337 interferes with angiogenesis in a similar way to conventional 


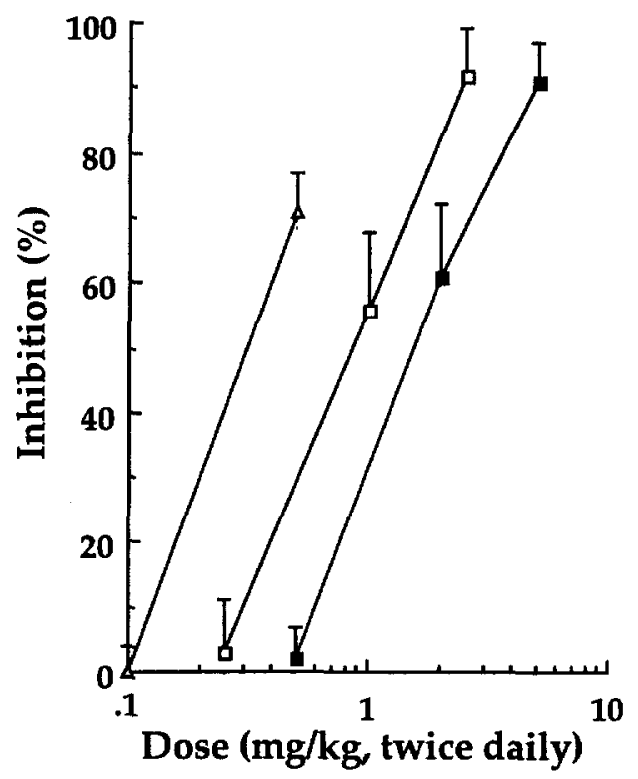

Figure 3. Dose-response curves for the inhibition of gastric ulcer rate from days 8-15 by indomethacin $(\triangle)$, diclofenac $(\square)$, and L-745,337 ( $\square$ ) in a chronic cryo-ulcer model. ID 50 values for the doses administered twice daily are $0.4 \mathrm{mg} / \mathrm{kg}, 0.8 \mathrm{mg} / \mathrm{kg}$, and $1.7 \mathrm{mg} / \mathrm{kg}$ for indomethacin (sc), diclofenac (ig), and L-745,337 (ig), respectively. The difference between indomethacin and L-745,337 is significant $(p<0.001)$; in contrast, the difference between diclofenac and L-745,337 is not significant

NSAIDs explains at least in part the ulcer healing delay. There is increasing evidence from recent studies that COX-2, albeit largely absent in healthy mucosa is abundantly expressed at the edge of healing ulcers [34-36]. This is not really surprising since the COX-2 is abundant in inflammation such as in arthritic exudates. At the ulcer edge COX-2 expression has been verified by immunohistochemical techniques in microvessels [36,37] and macrophages. This has recently been confirmed with molecular biology techniques [37] by a Japanese group which has also confirmed in a mouse model that healing of acetic acid ulcers is delayed by a COX-2 inhibitor.

There is also an explanation for the conflicting results obtained with diclofenac coupled with an NO donor. In their study, Elliot et al. [23] supplied some data suggesting that this compound is not delaying healing of ulcers in the rat acetic acid model, but even slightly accerating ulcer cicatrization. Their study has, however, the limitation that NSAID medication was limited to the first week, in which all NSAIDs interfere only minimally with ulcer healing, as clearly outlined in our ulcer model, which allows complete analysis of the healing kinetics. 


\section{CONCLUSION}

Our studies have clearly outlined that for prediction of gastric tolerance a clear distinction is necessary between cytoprotective and healing properties of drugs interfering with the cylco-oxygenase and lipoxygenase pathway of prostaglandin generation. These studies do not, however, exclude the possibility that these novel NSAIDs offer a therapeutic advantage due to better tolerance during short-term administration. Further studies are, however, necessary to determine whether this optimized gastrointestinal safety profile is maintained during long-term application. Caution appears to be particularly warranted against their uncritical application in patients suffering from peptic ulcer disease.

\section{REFERENCES}

1. Halter F, Hurlimann S, Inauen W. Pathophysiology and clinical relevance of Helcobacter pylori. Yale J Biol Med. 1992;65:625-38.

2. Hawkey CJ. Non-steroidal anti-inflammatory drugs and peptic ulcers. Br Med J. 1990;300:278-84.

3. Peura DA, Graham DY. Helicobacter pylori: consensus reached: peptic ulcer is on the way to becoming an historic disease (editorial). Am J Gastroenterol. 1994;89:1137-9.

4. Armstrong HP, Blower AL. Non-steroidal anti-inflammatory drugs and life-threatening complications of peptic ulceration. Gut. 1987;28:527-532.

5. Somerville K, Faulkner G, Langman $\mathbf{M}$. Non-steroidal anti-inflammatory drugs and bleeding peptic ulcer. Lancet. 1986;1:462-4.

6. Halter F, Weber B, Huber T, Eigenmann F, Frey MP, Ruchti C. Diaphragm disease of the ascending colon. Association with sustained-release diclofenac. J. Clin. Gastroenterol. 1993;16:74-80.

7. Inauen W, Wyss PA, Kayser S et al. Influence of prostaglandins, omeprazole, and indomethacin on healing of experimental gastric ulcers in the rat. Gastroenterology. 1988;95:636-41.

8. Wang JY, Yamasaki S, Takeuchi K, Okabe S. Delayed healing of acetic acid-induced gastric ulcers in rats by indomethacin. Gastroenterology. 1989;96:393-402.

9. Robert A, Nezamis JE, Lancaster C, Hanchar AJ. Cytoprotection by prostaglandins in rats. Prevention of gastric necrosis produced by alcohol, $\mathrm{HCVL}, \mathrm{NaOH}$, hypertonic $\mathrm{NACl}$, and thermal injury. Gastroenterology. 1979;77:433-43.

10. Hirose H, Takeuchi $\mathbf{K}$, Okabe S. Effect of indomethacin on gastric mucosal blood flow around acetic acid induced gastric ulcers in rats. Gastroenterology. 1991;100:1259-65.

11. Graham DY, Agrawal NM, Roth SH. Prevention of NSAID-induced gastric ulcer with misoprostol: multicentre, double-blind, placebo-controlled trial. Lancet. 1988;2:1277-80.

12. Schmassmann A, Tarnawski A, Peskar BM, Varga L, Flogerzi B, Halter F. Sequential assessment of gastric ulcer healing in rats: reversal of indomethacin-induced effects by omeprazole. Am J Physiol. 1994;268:G276-85.

13. Levi S, Goodlad RA, Lee CY et al. Inhibitory effect of non-steroidal anti-inflammatory drugs on mucosal cell proliferation associated with gastric ulcer healing. Lancet. 1990;336:840-3.

14. Ogihara $Y$, Okabe S. Mechanism by which indomethacin delays gastric ulcer healing in the rat: Inhibited contraction of the ulcer base. Jpn J Pharmacol. 1993;61:123-31.

15. Graham DY, Smith JL, Spjut HJ, Torres E. Gastric adaptation studies in humans during continuous aspirin administration. Gastroenterology. 1988;95:327-33.

16. Hawkey CJ, Walt RP. Prostaglandins for peptic ulcer. A promise unfulfilled. Lancet. 1986;2:1084-7.

17. Dorta G, Nicolet D, Vouillamoz D, Margalith D, Blum Al, Armstrong D. Effects of misoprostol on healing and prevention of biopsy-induced gastroduodenal lesions occuring during the administration of diclofenac in volunteers. Aliment Pharmacol Ther. 1996;10:563-9.

18. Walan A, Bader JP, Classen $M$ et al. Effect of omeprazole and ranitidine on ulcer healing and relapse rates in patients with benign gastric ulcer. N Engl J Med. 1989;320:69-75.

19. Wang JY, Nagai H, Okabe S. Effect of omeprazole on delayed healing of acetic acid-induced gastric ulcers in rats. Jpn J Pharamcol. 1990;54:82-5. 
20. Sirko SP, Schindler R, Doyle MJ, Weisman SM, Dinarello CA. Transcription, translation and secretion of interleukin 1 and tumor necrosis factor: effects of tebufelone, a dual cyclooxygenase/5-lipoxygenase inhibitor. Eur J Immunol. 1991;21:243-50.

21. Halter F, Rainsford KD, Sirko SS, Schmassmann A. NSAID-induced mucosal injury: analysis of gastric toxicity of new generation NSAIDs: ulcerogenicity compared with ulcer healing. Yale J Biol Med. (in press).

22. Wallace JL, Reuter B, Cicala C, McKnight W, Grisham MB, Cirino G. Novel nonsteroidal antiinflammatory drug derivatives with markedly reduced ulcerogenic properties in the rat. Gastroenterology. 1994;107:173-9.

23. Elliott SN, McKnight W, Cirino G, Wallace JL. A nitric oxide-releasing nonsteroidal anti-inflammatory drug accelerates gastric ulcer healing in rats. Gastroenterology. 1995;109:524-30.

24. Wallace JL, Pittman QJ, Cirino G. Nitric oxide-releasing NSAIDs: a novel class of GI-sparing antiinflammatory drugs. Agents Actions. 1995;46:121-9.

25. Benoni. G, Terzi M, Adami A, Grigolini L, Del Soldato P, Cuzzolin L. Plasma concentrations and pharmacokinetic parameters of nitrofenac using a simple and sensitive HPLC method. J Pharm Sci. 1995;84:93-5.

26. Wallace JL, Reuter B, Cicala C, McKnight W, Grisham M, Cirino G. A diclofenac derivative without ulcerogenic properties. Eur J Pharmacol. 1994;25:249-55.

27. Conforti A, Donini M, Brocco G, Del Soldato P, Benoni G, Cuzzolin L. Acute anti-inflammatory activity and gastrointestinal tolerability of diclofenac and nitrofenac. Agents Actions. 1993;40:176-80.

28. Reuter BK, Cirino G, Wallace JL. Markedly reduced intestinal toxicity of a diclofenac derivative. Life Sci.1994;55:1-8.

29. Cuzzolin L, Conforti A, Donini M, Adami A, Del Soldato P, Benoni G. Effects on intestinal microflora, gastrointestinal tolerability and antiinflammatory efficacy of diclofenac and nitrofenac in adjuvant arthritic rats. Pharmacol Res. 1994;29:89-97.

30. Roth GJ, Siok CJ, Ozols J. Structural characteristics of prostaglandin synthase from sheep vesicular gland. J Biol Chem. 1980;255:1301-4.

31. Williams CS, Dubois RN: Prostaglandin endoperoxide synthase: Why two isoforms? Am J Physiol. 1996;270:G393-G400.

32. Boyce S, Chan CC, Gordon R et al. L-745,337: A selective inhibitor of cyclo-oxygenase-2 elicits antinociception but not gastric ulceration in rats. Neuropharmacology. 33;1994:1609-11.

33. Chan CC, Boyce S, Brideau C et al. Pharmacology of a selective oxygenase-2 inhibitor, L-745,337: A novel nonsteroidal anti-inflammatory agent with an ulcerogenic sparing effect in rat and nonhuman primate stomach. J Pharmacol Exp Ther. 1995;274:1531-7.

34. Schmassmann A, Tarnawski A, Peskar BM, Varga L, Flogerzi B, Halter F. Influence of acid and angiogenesis on kinetics of gastric ulcer healing in rats: interaction with indomethacin. Am J Physiol. 1995;268:G276-85.

35. Schmassmann A, Netzer P, Flogerzi B, Halter F. Role of cyclooxygenase-1 and -2 in gastric ulcer healing in rats. Gastroenterology. 1997;112A:283.

36. Tarnawski A, Wahlstrom K, Gergely H, Sarfeh IJ. Expression of cyclooxygenase-1 and -2 (COX-1 and COX-2) in normal gastric mucosa. Effect of antacid (hydrotalcit) treatment.

Gastroenterology. 1996;110:A275.

37. Mizuno H, Sakamoto C, Matusda $K$ et al. Induction of cyclooxygenase-2 in gastric mucosal lesions and its inhibition by the specific antagonist delays healing in mice. Gastroenterology. 1997;112:387-97.

Manuscript received 15 Aug. 97.

Accepted for publication 22 Aug. 97. 